\title{
FUNÇÃO SOCIOAMBIENTAL DA PROPRIEDADE E A NECESSIDADE DA REFORMA ÁGRARIA SOB A ÉGIDE DO DIREITO AGRÁRIO
}

Gabriela Esther Nascimento dos Santos

Licenciada Plena em Filosofia (UFPA), estudante de Direito (FIBRA), integrante do grupo de pesquisa Grupo de Filosofia Temática (GFT). E-mail: gabi.phi.adv@gmail.com

\section{RESUMO}

O presente trabalho tem como escopo discorrer sobre a propriedade e sua função socioambiental, bem como retratar o instituto da reforma agrária neste cenário. Para isto, inicialmente será traçado um contexto histórico que retratará de forma escorreita como o modo de colonização influenciou na forma atual de divisão de terras. Ato contínuo, serão expostas as principais normas que acompanham o direito agrário no Brasil durante o interregno da colonização até a atualidade, de maneira que seja exteriorizada a relação deste ramo autônomo do direito com a reforma agrária, tal como a função socioambiental da propriedade. Por fim, será feita uma análise a respeito da efetividade de tais regramentos.

PALAVRAS-CHAVE: Função Socioambiental. Reforma Agrária. Direito Agrário. Propriedade.

\section{SOCIO-ENVIRONMENTAL FUNCTION OF PROPERTY AND THE NEED FOR AGRICULTURAL REFORM UNDER THE AGRICULTURAL LAW}

\begin{abstract}
The present work has as scope to discuss the property and its socioenvironmental function, as well as portraying the institute of agrarian reform in this scenario. For this, initially will be traced a historical contexto that will portray smoothly as the way of colonization influenced in the current form of division of landes. Immediately thereafter, the main norms that accompany the agrarian right in
\end{abstract}


Brazil during the interregnum of colonization until the present time will be exposed, so that the relationship of this autonomous branch of law with the agrarian reform will be externalized, as well as the socioenvironmental function of the property. Finally, nalysis will be made about the effectiveness of such rules.

KEYWORDS: Socio-environmental Function. Agrarian Reform. Agrarian Law. Property.

\section{INTRODUÇÃO}

"Minha terra tem palmeiras onde canta o sabiá..." (GONÇALVES DIAS, 1843). Os versos de Canção do Exílio não se tratam meramente de um poema romântico. De fato, o território brasileiro é diferenciado, possuindo uma imensa biodiversidade, sendo formado por vastas riquezas minerais, belezas naturais, terras férteis e biomas variados.

Não obstante, sabe-se que o acesso a tais virtudes se deu de forma desigual e que seu reflexo se estende à atualidade, posto que nem todos tiveram e nem têm o privilégio da propriedade da terra. Demais disso, aqueles que o detêm nem sempre cumprem com a finalidade social adequada e também equilibrada para a preservação do meio ambiente, indo em oposição ao seguinte princípio norteador do direito de propriedade, qual seja: a função socioambiental.

Neste contexto, o presente trabalho cuida de analisar a função socioambiental da propriedade e seus meandros com o instituto da reforma agrária, à luz do direito agrário.

Diante disso, os motivos que levaram a este estudo surgiram do interesse pelo melhor conhecimento das normas que regem a relação entre o homem e a propriedade, mormente os princípios, leis e funções que norteiam a sociedade neste ramo. Ora, acomodar-se com o conhecimento geral do art. $5^{\circ}$, inc. XXII da Constituição Federal, que garante o direito de Propriedade, é manter-se raso frente a um assunto de tamanha relevância que é a função social da propriedade; é estar alienado à existência de leis especiais, como a Lei de Terras, que deu início à regulamentação da propriedade privada no Brasil, e o Estatuto da Terra que inovou com a criação do instituto da reforma agrária.

Paralelamente a isso, nasce a seguinte questão: no que concerne à política de reforma agrária, bem como as normas que a instituem, como leis e princípios, há eficácia na aplicabilidade de tais regramentos ou tratam-se de meros dispositivos mortos? É o que busca responder a presente pesquisa. 
A seu turno, objetiva-se com esta pesquisa expor conceitos, definições e instrumentos necessários para o conhecimento mais aprofundado a respeito da propriedade, de sua função socioambiental e de seus institutos anexos, como a reforma agrária. Tudo isso sem incorrer de forma verborrágica, para que a leitura tenha seu valor e não seja cansativa.

Em sendo assim, por ser a função social um conteúdo basilar do direito de propriedade, sendo esta traçada desde os primórdios da colonização, é de suma importância que a sociedade tenha noção de seus direitos e deveres jurídicos neste aspecto, pelo que este trabalho contribuirá para isto. Do mesmo modo, servirá ao operador do direito, uma vez que engradecerá seus conhecimentos sobre o assunto em questão, podendo aplicá-los futuramente, seja na docência ou em defesa de interesses individuais ou coletivos.

\title{
2METODOLOGIA
}

Para o desenvolvimento deste trabalho, teremos como utilização a pesquisa bibliográfica como principal elemento para fundamentar as reflexões, nos termos propostos por Severino (2007):

\begin{abstract}
A pesquisa bibliográfica é aquela que se realiza a partir do registro disponível, decorrente de pesquisas anteriores, em documentos impressos, como livros, artigos, teses etc. Utiliza-se de dados ou de categorias teóricas já trabalhados por outros pesquisadores e devidamente registrados. Os textos tornam-se fontes dos temas a serem pesquisados. O pesquisador trabalha a partir das contribuições dos autores dos estudos analíticos dos textos (SEVERINO, 2007, p. 112).
\end{abstract}

Com base na revisão bibliográfica e com o auxílio de um curta-metragem sobre a temática, este trabalho buscou produzir uma explicação de como a doutrina jurídica expõe a legislação brasileira e como esta legislação se dá na prática no âmbito da sociedade brasileira.

Para tanto, nas primeiras seções é possível acompanhar a evolução histórica da divisão de terras brasileiras desde o Brasil Colônia, analisando e apresentando as formas propostas para divisão de terras. Em seguida, pontuasse a evolução no âmbito legislativo, com a criação de leis e decretos que pudessem padronizar e regularizar as terras brasileiras.

A principal análise do trabalho gira em torno do entendimento de como foi se dado a distribuição de terras brasileiras e como a Reforma Agrária é necessária para que a terra possa exercer a sua finalidade social, tendo uso e utilidade efetiva.

Ressalta-se que para além da análise doutrinária e científica, utilizou-se uma entrevista 
realizada em um canal da internet com entrevistados confiáveis, sendo um Professor da Universidade de Brasília e um Economista que a época da entrevista ocupava a Superintendência do INCRA do Rio de Janeiro, com o objetivo de através da exposição de suas experiências e dificuldades diárias se possa refletir sobre o fomento e a importância da defesa da Reforma Agrária no Brasil.

\section{EVOLUÇÃO HISTÓRICA}

\subsection{CONSOLIDAÇÃO DA PROPRIEDADE RURAL NO BRASIL}

Ávidos pela conquista de novas terras, Portugal e Espanha, duas maiores potências da época, entabularam um pacto denominado Tratado de Tordesilhas, que consistia em uma divisão imaginária das terras eventualmente "descobertas" e as que por ventura viessem por “descobrir". Em verdade, este acordo era um instrumento legal que determinava a quem pertenciam as propriedades.

Desta forma, o referido tratado foi aplicado ao Brasil por volta de 1494, pertencendo a parte direita ao Reino de Portugal e a esquerda à Coroa de Castela. Convém pôr em relevo a influência que a igreja católica possuía sobre o estado, o que pode ser visualizado no fato de um Papa, chamado Júlio II, ter ratificado o referido tratado.

Destaca-se que os habitantes originais do Brasil possuíam uma cultura muito diferente da dos europeus, fato que fez com que aqueles enfrentassem bastante preconceito por parte destes.

Outrossim, a economia adotada na época era de subsistência, voltada para o próprio consumo dos índios, como por exemplo, a caça, a pesca, a agricultura. No entanto, é interessante expor a descrição de Fausto (1996,

p. 20) a respeito de uma das tribos existentes:

\footnotetext{
“Os grupos Tupis praticavam a caça, a pesca, a coleta de frutas e a agricultura, mas seria engano pensar que estivessem intuitivamente preocupados em preservar ou restabelecer o equilíbrio ecológico das áreas por eles ocupadas. Quando ocorria uma relativa exaustão de alimentos nessas áreas, migravam temporariamente ou definitivamente para outras. De qualquer forma, não há dúvida de que, pelo alcance limitado de suas atividades e pela tecnologia rudimentar de que dispunham, estavam longe de produzir os efeitos devastadores da poluição de rios com mercúrio, ou da derrubada de florestas com motosserras, características das atividades dos brancos nos dias de hoje".
}

É nesse contexto que os portugueses adentraram, por volta de 1500 , dando início ao Complexitas - Rev. Fil. Tem., Belém, v. 4, n. 2 , p. 69-86, jul./dec. 2019 - ISSN: 2525-4154 
período pré-colonial que se caracteriza basicamente pela atividade econômica voltada para a extração do pau-brasil, já que ainda não se conheciam as outras riquezas do território adentro.

Por volta de 1534, frente à ameaça de invasões estrangeiras, Portugal decide colonizar a terra, e o faz criando as famigeradas Capitanias Hereditárias, que consistiram na divisão do litoral em 15 lotes de terras doados aos membros de confiança da Coroa, designados Donatários, com o intuito de ocupação, povoamento e desenvolvimento. Fato é que as Capitanias eram uma espécie de unidade administrativa, dotada de caráter político e territorial. Começa-se assim a ser desenhado o período colonial brasileiro.

Neste passo, importa dizer que os donatários eram possuidores da terra, mas não os proprietários. Assim, não podiam dispor da coisa, sendo vedado alienar ou dividir seu lote. De sorte que cabia somente ao rei este privilégio. Contudo, por meio da posse eram dados ao donatário poderes econômicos e administrativos sobre a capitania. Assim, por exemplo, este poderia efetuar a cobrança de tributos, como também doar Sesmarias, respectivamente.

Com o tempo, o sistema de Capitanias hereditárias fracassou devido a diversos fatores, como falta de recursos, conflitos indígenas, inexperiência dos donatários, dentre outros, mas deixou uma fagulha que posteriormente se expandiu, qual seja, o latifúndio, resultante da concessão desordenada de terras (Sesmarias).

Posteriormente, instalou-se o Governo Geral que teve um cunho mais centralizado e organizado. Ressalta-se, que o sistema de latifúndios, frutos das capitanias, foram mantidos pelo Governo Geral, uma vez que o Governador passou a conceder as doações.

\subsection{SISTEMA SEMARIAL NO BRASIL (1531 A 1822)}

Consoante Fausto (1996, p. 25), Sesmaria era uma extensão de terra virgem cuja propriedade era doada a um sesmeiro, com a obrigação - raramente cumprida - de cultivá-la no prazo de cinco anos e de pagar o tributo devido à Coroa.

Implementadas de forma legal pela Carta Foral em 1531, as Sesmarias também tinham o objetivo de proteção contra invasões estrangeiras, povoamento e ocupação. No entanto, diferentemente das capitanias hereditárias, se estenderam a terras mais profundas do território e não somente ao litoral. Ademais, havia um certo caráter econômico, na medida em que se deu ênfase à produção agrícola, tendo como objetivo o sustento da Colônia.

Para Opitz (2016), a finalidade das Sesmarias era aumentar a produção, pois, se todas as terras que haviam no Reino fossem cultivadas, "haveria pão de sobejo para toda a gente, e não 
também, o repovoamento, uma vez que havia algumas zonas coloniais com grande densidade demográfica que tinham acentuada emigração para outras terras - sendo estas férteis e abundantes - ressaltando que isto não ocorre na conjuntura atual do Brasil.

Em sendo assim, ao sesmeiro era dado o domínio útil da terra, devendo cumprir alguns requisitos para com esta, caso tivesse a intenção de ser o proprietário, quais sejam: dar aproveitamento à terra, isto é, destinação àquela área; delimitar a extensão da terra, medindo e demarcando o espaço; ter o registro da carta; pagar o foro e obter a confirmação do rei.

Entretanto, Opitz (2016) aduz que os colonizadores preferiam manter-se somente com a posse, restringindo-se ao cultivo, do que percorrer uma difícil missão hierárquica de ir até ao governador e em seguida ao rei para se obter o domínio pleno do título. Nessa condição eram denominadas "Sesmaria caídas em comisso", isto é, terras que não cumpriram as condições de doação.

A influência das Sesmarias na formação dos latifúndios foi reflexo do sistema feudal que predominava na época, o que foi um erro, na medida em que, segundo Opitz (2016), não foi adotado nenhum plano de cultivo e distribuição das terras brasileiras, o que gerou distorções que repercutem atualmente. Fato é que houve grande quantidade de terra entregue a um pequeno número de pessoas. Tal arrumação tornou-se o berço da formação dos latifúndios e minifúndios. Em 1822, foi editada a resolução nº 76 que suspendeu a doação por Sesmaria. Estava formado o período Senhorial.

\subsection{SISTEMA SENHORIAL (1822 A 1850)}

Conhecido como período áureo da posse, trata-se de um lapso sem qualquer norma ou entidade disciplinando ou ordenando a aquisição de terras.

Aqui, predominavam as ocupações desordenadas, sendo um meio de aquisição em que os colonos invadiam e se apossavam de fatias de terras. Emgeral, eram espaços ocupadas por índios e sem nenhum valor comercial, restando ao invasor a economia de subsistência. Desse período até 1850, quando a Lei de Terras foi decretada, a ocupação tornou-se a única forma de se obter terras. Em verdade, esta formação gerou grandes efeitos, na medida em que, para Emília Costa (1999, p. 176) as posses resultantes de ocupações aumentaram de forma incontrolável e os posseiros ocuparam grandes extensões de terras mal delimitadas.

A expansão fez surgir grandes fazendeiros, que implantaram o sistema plantation no 
qual o café era o produto principal. Ocorre que nesse período o Brasil estava sofrendo pressões da Inglaterra por conta da escravidão, o que gerou problemas para os posseiros, posto que não tinham a propriedade legalizada e ainda estavam com a força de trabalho ameaçada.

A situação caótica da propriedade rural e os problemas da força de trabalho impeliram os setores dinâmicos da elite brasileira a reavaliar as políticas de terras e do trabalho (COSTA, 1999, p. 176). Esta ocorrência levou à tentativa de regularizar a propriedade através da Lei de Terras.

\subsection{SISTEMA MODERNO (1950 AOS DIAS ATUAIS)}

A Lei $n^{\circ}$ 601/1850, Lei de Terras, surge de uma necessidade por parte do Estado em distinguir a posse, propriedade pública e privada. Trouxe as diretrizes que faltavam ao período Senhorial, pois a partir dela o Estado passou a vender as propriedades e não mais a conceder.

Para Emília Costa (1999, p. 176), a Lei de Terras é a expressão de interesses da elite da época e representou uma tentativa de regularizar a propriedade rural e o fornecimento de trabalho, de acordo com as novas necessidades e possibilidades do período.

Em sendo assim, a proposta era que toda terra que não estivesse sendo utilizada de forma apropriada ou ocupada seria considerada pública. É o surgimento das terras devolutas (art. $3^{\circ}$ da Lei $n^{\circ} 601 / 1850$ ). De fato, o artigo $1^{\circ}$ da referida lei fala sobre o instituto da compra e venda, dispondo sobre a proibição de aquisições de terras devolutas por outra forma que não seja esta.

Em verdade, esta Lei dificultou a aquisição de terras pela sociedade mais pobre, posto que as propriedades eram vendidas a preços altos, o que impossibilitava o acesso à grande parte da população. Por este motivo, Emília Costa (1999, p. 180) assevera que esta Lei supriu a mão de obra da elite, na medida em que a grande massa do povo brasileiro e também os imigrantes não tinham condições financeiras de comprar seus lotes. Em sendo assim, o que restava a título de oportunidade para a sobrevivência era o trabalho nas fazendas.

Outro ponto importante a ser ressaltado é a questão das Sesmarias caídas em comisso. Houve, por parte desta Lei, a tentativa de revalidá-las. Assim, nos termos do art. $4^{\circ}$, as terras que estivessem com atividade voltada para o cultivo seriam revalidadas, ainda que não atendessem aos demais requisitos vistos anteriormente.

\section{DIREITO AGRÁRIO}




\title{
4.1.DIREITO AGRÁRIO (PRINCÍPIOS)
}

O Direito Agrário é um ramo autônomo do direito que regulamenta a relação existente entre o homem e a propriedade rural. De acordo com Opitz (2016), "Direito Agrário é o conjunto de normas jurídicas concernentes ao aproveitamento do imóvel rural”. $\mathrm{O}$ autor destaca a grande afinidade que este direito tem com a economia rural, fato que justifica a intervenção estatal no domínio privado. Desta forma, pode-se afirmar que Direito Agrário e Economia estão umbilicalmente ligados.

A Emenda Constitucional $n^{\circ} 10$ de 1964, em seu artigo $5^{\circ}$, determinou a competência da União para Legislar sobre Direito Agrário, o que se manteve na atual Constituição Federal no art. 22 , inc. I.

\subsection{PRINCÍPIO DA FUNÇÃO SOCIAL DA PROPRIEDADE}

Este princípio é regulamentado por diversas Leis, desde a Constituição de 1988 até Leis mais específicas como o Estatuto da Terra.

Rocha (2015, p. 55), sobre a função social afirma que:

\begin{abstract}
"Aproveitamento racional e adequado, utilização adequada dos recursos naturais disponíveis e preservação do meio ambiente, observância das disposições que regulam as relações de trabalho, exploração que favoreça o bem-estar econômico dos proprietários e trabalhadores (art. 186 da CF). Penalização dos que possuem a terra sem que a mesma cumpra a sua função social”.
\end{abstract}

Neste sentido, a Constituição Federal de 1988 em seu art. 5º inc. XXII, garante o direito de propriedade. Entretanto, exige que seja cumprida a função social, conforme delimitado no inciso seguinte, XXIII.

Do mesmo modo no art. 170, inc. III da CF consta uma restrição quanto ao direito de propriedade privada, na medida em que este deve ser exercido em

consonância com a função social, devendo promover o desenvolvimento econômico do país de forma digna e justa.

Outrossim, o Capítulo III da CF trata sobre a Política Agrícola e Fundiária e da Reforma Agrária, dando ao art. 184 a possibilidade de haver desapropriação por interesse social, a qual será avaliada de acordo com os requisitos do art. 186 da CF, qual sejam: 
"I - aproveitamento racional e adequado; II - utilização adequada dos recursos naturais disponíveis e preservação do meio ambiente; III - observância das disposições que regulam as relações de trabalho; IV - exploração que favoreça o bem-estar dos proprietários e dos trabalhadores".

Além disso, o art. $2^{\circ}$ da Lei 4.504/64, Estatuto da Terra, novamente garante o direito de propriedade, mas condiciona à função social aos seguintes critérios:

“a) Favoreça o bem-estar dos proprietários e dos trabalhadores que nela labutam, assim como de suas famílias; b) mantém níveis satisfatórios de produtividade; c) assegura a conservação dos recursos naturais; d) observa as disposições legais que regulam as justas relações de trabalho entre os que a possuem e a cultivem".

Nesse diapasão, a Função Social da Propriedade é condição limitante do exercício de propriedade. A partir destes dispositivos supra expostos, vê-se que a intenção do legislador é melhorar a distribuição de riquezas, sendo uma tentativa de reduzir as distorções históricas vistas anteriormente.

\subsection{PRINCÍPIO DA PROTEÇÃO ESPECIAL À PEQUENA EMPRESA AGRÁRIA}

O Estatuto da Terra, Lei $n^{\circ} 4.504 / 64$, define em seu art. $4^{\circ}$, inc. II, o que vem a ser propriedade familiar, sendo:

"O imóvel rural que, direta e pessoalmente explorado pelo agricultor e sua família, lhes absorva toda a força de trabalho, garantindo-lhes a subsistência e o progresso social e econômico, com área máxima fixada para cada região e tipo de exploração, e eventualmente trabalho com a ajuda de terceiros".

Entende-se que parte da ideia de que a propriedade seja produtiva e que ao mesmo tempo sirva para a conservação do núcleo familiar. Desta forma, a pequena propriedade rural tem uma proteção especial no art. $5^{\circ}$, inc. XXVI da CF, na medida

em que, em sendo trabalhada pela família, isto é, usada para o sustento, é vedada a sua penhora para pagamentos de débitos relacionados à sua atividade produtiva.

Ademais, a CF/88 em seu art. 153, $\S 4^{\circ}$, inciso II, confere imunidade tributária ao pequeno proprietário rural que não possua outro imóvel, ficando isento do recolhimento do Imposto sobre a Propriedade Territorial Rural (ITR). Nada mais é que um incentivo ao bemestar do pequeno produtor que cumpre com a função social. 


\subsection{PRINCÍPIO DO ACESSO E DISTRIBUIÇÃO DE TERRA}

Rocha (2015, p. 57) aduz que o Estado deve garantir a todos o acesso à terra, sendo que para aqueles que não têm condições financeiras deverá ser oportunizado através da desapropriação de imóveis improdutivos, além de subsídio para aquisição. Este princípio pode ser visualizado no art. 191 da $\mathrm{CF} / 1988$ que trata da usucapião para aquele que detém a posse de imóvel como moradia, sendo rural ou urbano, tornando-o produtivo por seu trabalho ou de sua família por cinco anos ininterruptos, desde que não seja superior a cinquenta hectares.

Do mesmo modo reza o art. $2^{\circ}, \S 3^{\circ}$ do Estatuto de Terras que garante ao agricultor o direito de permanecer na terra que cultive. Veja que há um direito limitado por uma obrigação, qual seja, a produção.

\subsection{PRINCÍPIO DO INTERESSE PÚBLICO SOBRE O PARTICULAR}

Parte do princípio de que a propriedade não deve atender somente aos anseios individuais do proprietário, mas sim ao interesse social. Assim, quando aquele vai de encontro a este, o que prevalece é a coletividade. Ressalta-se o art. $4^{\circ}$, incisos II e III, do Estatuto de Terras, que remetem à propriedade familiar protegida pelo legislador e art. 65 que impede a divisão de área inferiores a um módulo rural.

\subsection{PRINCÍPIO DO RIGOR ESPECIAL PARA A PROPRIEDADE IMPRODUTIVA}

Para Rocha (2015, p. 58) este princípio designa que "a propriedade que não alcança os coeficientes mínimos de produtividade fixados pelo INCRA será objeto de desapropriação".

A desapropriação é a exceção. A regra é que a propriedade cumpra a sua função social e os demais princípios vistos anteriormente. Ocorre que não cumprindo poderá o Estado intervir na propriedade. Entretanto, existem algumas destas que não podem ser desapropriadas, como a pequena e média propriedade rural (desde que seu proprietário não possua outra) e a propriedade produtiva, conforme art. 185, inc. I e II da CF/88.

Este princípio também se traduz em forma de sanções, como no caso do art. $153, \S 4^{\circ}$, inc. I, que prevê o aumento de impostos sobre as propriedades improdutivas. 


\subsection{PRINCÍPIO DA PRESERVAÇÃO DA BIODIVERSIDADE}

Aqui, busca-se a preservação dos ecossistemas, dos recursos naturais, do meio ambiente como um todo.As normas jurídicas agroambientais devem limitar o uso dos recursos naturais em função da capacidade produtiva e de regeneração dos mesmos para evitar seu esgotamento (ROCHA, 2015, p. 58).

Este princípio consta expressamente no art. 170, inc. VI da $\mathrm{CF} / 88$, em que a ordem econômica deve observar a defesa do meio ambiente. Do mesmo modo, o art. 186, inc. II relaciona a função social da propriedade rural à utilização adequada dos recursos naturais disponíveis e a preservação do meio ambiente.

Vê-se que a preservação da biodiversidade, assim como os demais princípios, delimita o direito de propriedade. $\mathrm{O}$ art. 225 da $\mathrm{CF} / 88$, por exemplo, impõe ao poder público o dever de assegurar a todos o direito ao meio ambiente ecologicamente equilibrado, sendo essencial à vida saudável.O legislador acentuou a proteção ao meio ambiente ao ponto de considerar a responsabilidade objetiva aquele que a descumpre, conforme art. 14, $\S 1^{\text {o }}$ da Lei 6.938/81.

\section{PROPRIEDADE E FUNÇÃO SOCIAL}

O direito de propriedade sofreu inúmeras mudanças ao longo do tempo. Na era moderna, acompanhou os ideais de liberdade e igualdade, o que pode ser identificado no art. $5^{\circ}$, inc. XXII, da CF/1988 em que tal direito é garantido. Este foi mantido na era contemporânea, porém ampliou-se, adaptando-se ao modo de eficácia social que surgira, conforme se verifica no inc. XXIII do referido artigo no qual vincula a propriedade à função social, sendo uma forma de dar aplicabilidade material à norma.

Nesse sentido, Mendes e Branco (2018, p. 329) afirmam que:

\footnotetext{
"A propriedade privada tradicional perdeu muito do seu significado como elemento fundamental destinado a assegurar a subsistência individual e o poder de autodeterminação como fator básico da ordem social. Como observado por Hesse, a base da subsistência e do poder de autodeterminação do homem moderno não é mais a propriedade privada em sentido tradicional, mas o próprio trabalho e o sistema previdenciário e assistencial instituído e gerido pelo Estado".
}

Conforme visto anteriormente, o direito de propriedade deve estar em sintonia com alguns princípios, em especial o da função social. Assim entendem Mendes e Branco (2018, p. 
343) ao destacarem que o direito de propriedade se encontra vinculado a interesses distintos daqueles do seu titular, resultando em significativa limitação à autonomia privada quanto ao exercício das suas prerrogativas.

A questão da limitação à propriedade no tocante ao cumprimento da política agrícola é aplicável tanto a terras privadas quanto a públicas. É o que se identifica no art. 188, e seus parágrafos, da $\mathrm{CF} / 88$, em que o Congresso Nacional deve deliberar sobre a alienação e concessão de terras públicas com área superior a 2.500 hectares, à exceção daquelas que se destinam à reforma agrária.

\subsection{DESAPROPRIAÇÃO DE IMÓVEL RURAL PARA FINS DE REFORMA AGRÁRIA}

Nos termos do art. 184 da CF/88, é de competência da União efetivar a desapropriação para fins de Reforma Agrária do imóvel rural que não esteja cumprindo a sua função social. Para isto, haverá um pagamento justo de indenização ao proprietário em títulos da dívida agrária, tendo 20 anos como limite de resgate, a partir do $2^{\circ}$ ano da emissão.

Convém pôr em relevo as exceções à desapropriação previstas na Constituição, como no caso do art. 185 , e parágrafos, da $\mathrm{CF} / 88$. Como se vê, há um interesse social direcionado à propriedade que cultiva. Mas também há proteção do pequeno e médio proprietário rural, considerando que se tratam de categorias sociais que merecem amparo especial, qual seja, a manutenção da base familiar.

Outrossim, merece destaque a informação dada por Mendes e Branco (2018,

p. 357) no sentido de que o STF decidiu que não pode haver desapropriação para reforma agrária de terra invadida, sendo irrelevante o fato de a invasão dar-se sobre parte ou totalidade do imóvel.

O que se pode observar diante do que já fora exposto é que a Reforma Agrária se iniciou tardiamente no Brasil. Quanto a isto, o Professor da Universidade de Brasília e Relator do Direito Humano à Terra, ao Território e à Alimentação, Sérgio Sauer, em entrevista ao Canal Futura no Youtube, se pronunciou afirmando que, em que pese a Reforma Agrária possuir dimensões econômicas e sociais importantes para o avanço do capitalismo, existe fundamentalmente uma dimensão política muito forte, uma vez que a terra sempre foi um instrumento de poder.

Da mesma maneira o economista Gustavo Solto de Noronha, Superintendente do 
INCRA no Rio de Janeiro, em entrevista ao canal supracitado, reforça a colocação do Professor quanto à dificuldade no acesso e distribuição de terras a todos, ressaltando que no Congresso Nacional existe a bancada ruralista, que é um setor político forte. Com isto, leva-se a crer que a eficácia da política da reforma agrária encontra barreiras na medida em que há conflitos de interesses, onde um setor com alta representatividade no Congresso Nacional concentra grandes propriedades de terras.

Essa contradição de concentrações sociais é geradora de grandes conflitos com a classe latifundiária. Logicamente, que sai em desvantagem é o camponês.

\section{LEIS ESPECIAIS}

\subsection{ESTATUTO DA TERRA E LEI Nº 8.629/93 E REFORMA AGRÁRIA}

Nos anos 60 havia uma tensão muito grande por parte dos camponeses quanto à questão das dificuldades em se obter terras. A população camponesa começara a se unir e pressionar o governo. Em sendo assim, para tentar amenizar esta situação, o Estado surge com uma alternativa de regulamentar melhores condições de trabalho e acesso à terra.

Nesse viés, a Emenda Constitucional nº 10 de 1964 fez surgir as primeiras ideias sobre desapropriação de propriedade territorial rural. Dias depois aprovou-se o Estatuto da Terra, Lei $n^{\circ} 4.504 / 64$.

Este Estatuto surgiu de uma necessidade em equilibrar a estrutura agrária tão dispare, especialmente em função do latifúndio que se consolidou. Além disso, introduziu o princípio da Função Social da propriedade rural como norma jurídica (ROCHA, 2015, p. 74).

Desta forma, o art. $1^{\circ}$ e $2^{\circ}$ regulamentam expressamente a Reforma Agrária e a Função Social da propriedade. Em verdade, o que se percebe é que o Estado assumiu a função de desapropriar imóveis improdutivos, combatendo os minifúndios e latifúndios, para dar dignidade a quem morava no campo e não tinha acesso a terras. Para isso, instituiu a Reforma Agrária.

De par isso, o artigo $1^{\circ}$ do Estatuto dita o conceito de Reforma Agrária, sendo o conjunto de medidas que visem promover melhor distribuição da terra, mediante modificações no regime de sua posse e uso, a fim de atender aos princípios de justiça social e ao aumento de produtividade.

No art. $2^{\circ}$, o Diploma também conceitua a política agrícola, sendo o conjunto de 
providências de amparo à propriedade da terra, destinado à economia rural, atividades agropecuárias, emprego, tudo em harmonia com a industrialização do país. A seu turno, o art. 16 do referido Estatuto dita os objetivos da Reforma Agrária traçada pelo estado, sendo: a promoção da justiça social, o progresso e o bem-estar do trabalhador rural e a extinção do latifúndio e minifúndio. Tudo isto levando-se em consideração o desenvolvimento econômico do país, isto é, a função social.

Impende destacar que o Estatuto da Terra justificou a desapropriação por interesse social ao atrelar os objetivos desta ao desenvolvimento sustentável. Em razão disso, implementou no art. 18:

“a) Condicionar o uso da terra à sua função social; b) a justa e adequada distribuição da propriedade; c) obrigar a exploração racional da terra; d) permitir a recuperação social e econômica de regiões; e) estimular pesquisas pioneiras, experimentação, demonstração e assistência técnica; f) efetuar obras de renovação, melhoria e valorização dos recursos naturais; g) incrementar a eletrificação e a industrialização no meio rural; h) facultar a criação de áreas de proteção à fauna, à flora ou a outros recursos naturais, a fim de preservá-los de atividades predatórias".

Importante ressaltar ainda que a Reforma Agrária não consiste somente em assentar os camponeses em uma propriedade. É preciso que o Estado dei o auxílio necessário para que aquele consiga produzir de forma equilibrada, cumprindo assim a função social. Nesse sentido, o art. 187, § $2^{\circ}$, da CF prevê o apoio Estatal no ramo da política agrícola e da Reforma Agrária, seja possibilitando o acesso a créditos, incentivando a tecnologia, possibilitando a habilitação para o trabalhador rural, dentre outros.

Em adição a este Estatuto há a Lei nº 8.629/93 que dispõe sobre a regulamentação dos dispositivos constitucionais referentes à Reforma Agrária. No art. 19 tem-se a condição para se tornar um beneficiário. Assim sendo, os títulos a serem concedidos observarão os seguintes princípios:

"I - ao desapropriado, ficando-lhe assegurada a preferência para a parcela na qual se situe a sede do imóvel; II - aos que trabalham no imóvel desapropriado como posseiros, assalariados, parceiros ou arrendatários; III aos que trabalham como posseiros, assalariados, parceiros ou arrendatários, em outros imóveis; IV - aos agricultores cujas propriedades não alcancem a dimensão da propriedade familiar; V - aos agricultores cujas propriedades sejam, comprovadamente, insuficientes para o sustento próprio e o de sua família. Parágrafo único. $\mathrm{Na}$ ordem de preferência de que trata este artigo, terão prioridade os chefes de família numerosa, cujos membros se proponham a exercer a atividade agrícola na área a ser distribuída". 
Atualmente quem detém a competência para aferir a produtividade do imóvel é o INCRA - Instituto Nacional da Colonização e Reforma Agrária. Ressalta-se que o IBRA, criado pelo Estatuto da Terra, conforme art. 16, Parágrafo único, tendo como função promover e elaborar o plano de execução da Reforma Agrária, foi então substituído pelo INCRA.

$\mathrm{O}$ art. $2^{\circ}$ e seus parágrafos da Lei $\mathrm{n}^{\circ}$ 8.629/93 confere competência ao INCRA para ingressar no imóvel particular para proceder com a vistoria no que tange ao cumprimento da função social.

Atualmente, em consulta ao site oficial do INCRA, no que tange à efetividade da reforma agrária, pode-se verificar que esta política não teve avanço nos últimos anos. A seguir consta um gráfico contendo o número de assentados por ano. A coleta se deu a partir de informações publicadas pela autarquia.

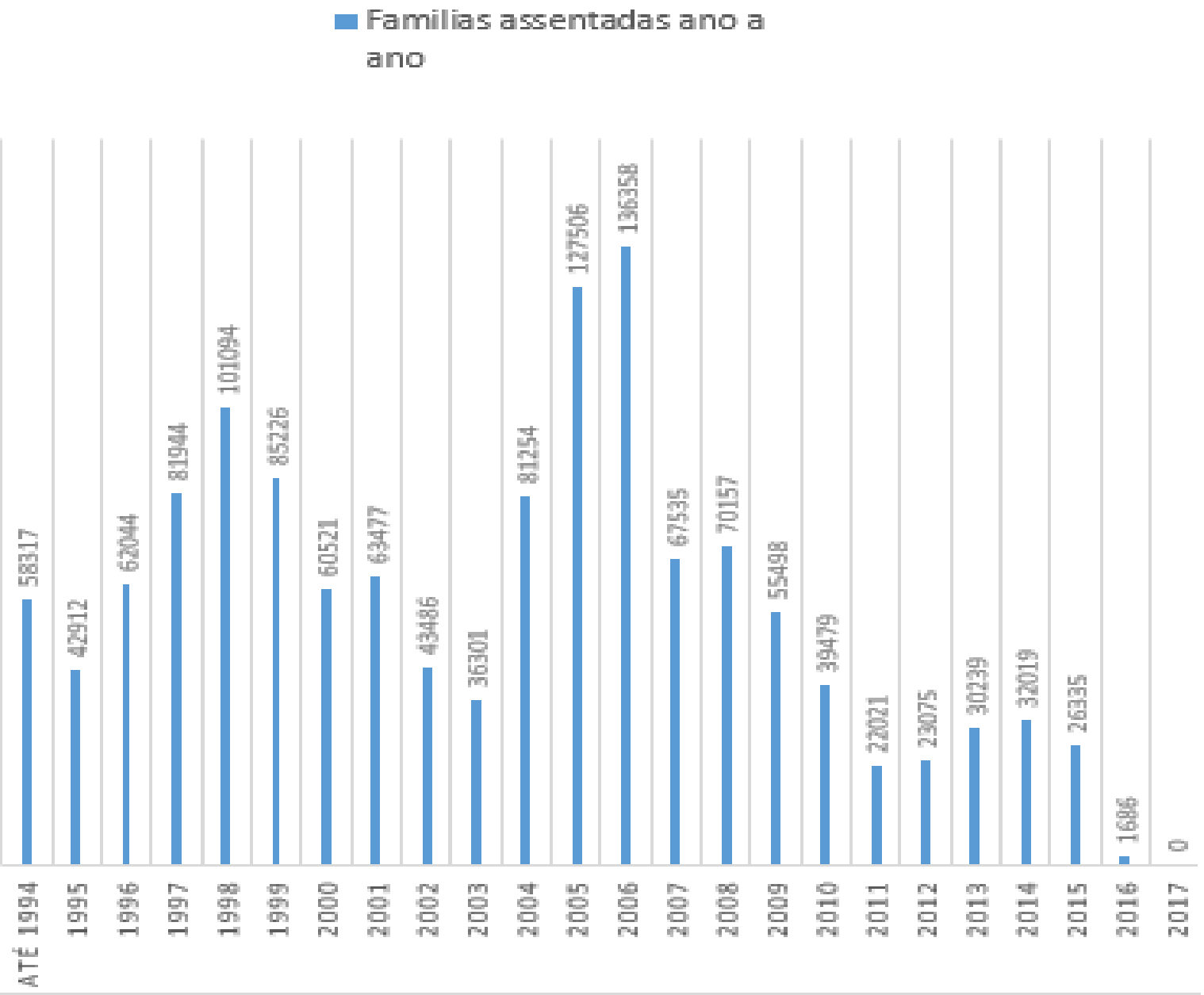

Fonte: site oficial do INCRA 
Da análise do gráfico abaixo verifica-se que o índice de assentados vem diminuindo. A título de amostragem, o ano de 2016 teve apenas 1.686 assentados, uma queda drástica em relação a 2015 em que o número foi de 26.335. Já em 2017, último ano informado pelo INCRA, o índice é mais drástico, posto que não houve assentados neste ano.

\section{CONSIDERAÇÕES FINAIS}

Observou-se nessa pesquisa que o Direito regula a esfera agrária no Brasil desde o início da colonização, podendo ser visto nas normas que definiram o tratado que dividiu o território; no regulamento de doações de Sesmarias que, inicialmente, partia das unidades administrativas denominadas Capitanias Hereditárias e após passou ao comando de um ente mais concentrado, qual seja, o Governo Geral; até mesmo após o lapso de diretrizes no Período Senhorial, em que houve ausência de regulamentação, pode-se verificar que as ocupações de terras, característica marcante desta época, tornaram-se costumes regulamentados no Período Moderno (fase posterior), sendo condicionada a regulamentação da propriedade ao requisito da produtividade.

Demais disso, é possível perceber que o Direito Agrário originalmente foi se amoldando de acordo com as necessidades predominantes a cada período, não se preocupando com efeitos futuros. A este despeito, cita-se a maneira desordenada em que ocorreu a distribuição de terras por Sesmarias e posteriormente por ocupações, que deram início a latifúndios e minifúndios, os quais são causas de miserabilidade camponesa e de inchaço urbano.

Todavia, essas consequências desastrosas transformaram o Direito Agrário, tornando-o mais social, coletivo, com uma concepção neoconstitucionalista ampliada na valorização da função social da propriedade, na medida em que tentou-se dar mais eficácia às normas existentes, seja pela política da reforma agrária, que valoriza os assentados, seja pela preocupação na preservação ambiental para a vida saudável. Tudo isto mantendo o modelo de economia capitalista predominante no país, isto é, a função social deve obedecer às regras da produtividade.

Em que pese a mudança do direito no tocante às dimensões sociais, em especial à reforma agrária, tem-se que as desigualdades se mantêm, e que as forças da elite dominante contribuem para o insucesso da melhor eficácia das normas de apoio ao cumprimento dos princípios e leis que direcionam para o acesso de todos a uma propriedade produtiva. A política 
da reforma agrária encontra entraves na medida em que há forças poderosas contrárias que predominam na esfera política.

Em sendo assim, de par com toda a pesquisa exposta, especialmente os dados concretos oficiais constantes no sítio eletrônico do INCRA, tem-se que a política da reforma agrária precisa ser mais eficaz. Não obstante o país ser extenso em área territorial, com grande potencial agrícola, seu aproveitamento se restringe a uma minoria latifundiária que permanece inamovível. Fato é que este formato de dominação que predomina sempre ocorreu. O cenário é mais rígido e social, mas os atores são os mesmos.

\section{REFERÊNCIAS BIBLIOGRÁFICAS}

\section{CONSTITUIÇÃOO FEDERAL.}

Disponível em:

〈wWw.planalto.gov.br>

BRANCO, Paulo G. Gonet; MENDES; Gilmar Ferreira

Curso de Direito

Constitucional. 13 ed. São Paulo:

Saraira, 2018.

COSTA, Emília Viotti da. $D a$ Monarquia à República: Momentos decisivos. 6 ed. São Paulo: Unesp, 1999.

EMENDA CONSTITUCIONAL $\mathrm{N}^{\circ}$ 10, DE 9 DE NOVEMBRO DE 1964. Disponível em: $<$ http://www.planalto.gov.br/ccivil_03 /Constituicao/Emendas/Emc_anterior $\underline{1988 / \text { emc1 0-64.htm> }}$

ESTATUTO DA TERRA.

Disponível em:

$<$ http://www.planalto.gov.br/ccivil_03

/leis/L4504.htm>

FAUSTO, Boris. História do Brasil: história do Brasil cobre um período de mais de quinhentos anos, desde as raízes da colonização portuguesa até nossos dias atuais. Edusp, 1996.

LEI DE TERRAS. Disponível em: <http://www.planalto.gov.br/ccivil 03 $\underline{\text { LEIS/L0601- 1850.htm }>}$

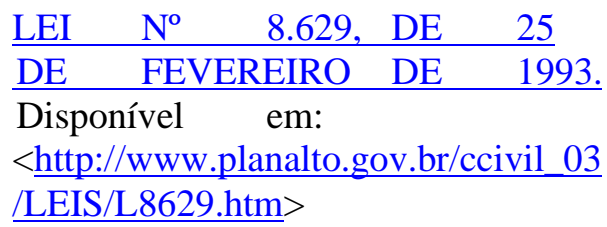

OPITZ, Silvia C. B.; OPITZ, Oswaldo. Curso Completo de Direito Agrário. 11. Ed. São Paulo: Saraiva, 2017.

Reforma Agráriano

Brasil. Disponível em:

$<$ https://www.youtube.com/watch? $\mathrm{v}=$ MZr-w8SGwgo>

ROCHA, Ibraim. Et al. Manual de Direito Agrário Constitucional: lições de direito agroambiental. Belo Horizonte: Fórum, 2015.

SEVERINO, Antônio Joaquim. Metodologia Científica. 23 ed. São Paulo: Cortez, 2007. 
SANTOS, G. E. S. Função Socioambiental da Propriedade e a Necessidade da Reforma Agrária sob a Égide do Direito Agrário.Complexitas - Rev. Fil. Tem. Belém, v. 4, n. 2, p. 69-86, jul./dec. 2019. Disponível em: http://www.periodicos.ufpa.br/index.php/complexitas/article/view/8102>. Acesso em: 30 de janeiro de 2020. 